\title{
MICHAEL EDWARDS, Dialogues singuliers sur la langue française
}

\section{Roberta Sapino}

\section{(2) OpenEdition}

\section{Journals}

\section{Edizione digitale}

URL: https://journals.openedition.org/studifrancesi/12328

DOI: 10.4000/studifrancesi. 12328

ISSN: 2421-5856

\section{Editore}

Rosenberg \& Sellier

\section{Edizione cartacea}

Data di pubblicazione: 1 avril 2018

Paginazione: 186

ISSN: 0039-2944

\section{Notizia bibliografica digitale}

Roberta Sapino, «MICHAEL EDWARDS, Dialogues singuliers sur la langue française», Studi Francesi [Online], 184 (LXII | I) | 2018, online dal 04 juillet 2018, consultato il 17 novembre 2021. URL: http://

journals.openedition.org/studifrancesi/12328; DOI: https://doi.org/10.4000/studifrancesi. 12328

Questo documento è stato generato automaticamente il 17 novembre 2021.

\section{@(๑) $\Theta \Theta$}

Studi Francesi è distribuita con Licenza Creative Commons Attribuzione - Non commerciale - Non opere derivate 4.0 Internazionale. 


\title{
MICHAEL EDWARDS, Dialogues singuliers sur la langue française
}

\author{
Roberta Sapino
}

\section{NOTIZIA}

MICHAEL EDWARDS, Dialogues singuliers sur la langue française, Presses Universitaires de France, 2016, $214 \mathrm{pp}$.

1 «Pourquoi es-tu devenu un écrivain français?» (p. 32). È per rispondere a questa domanda che Michael EDWARDS, primo intellettuale inglese a essere stato eletto all'Académie française, concepisce i Dialogues.

2 La riflessione dell'autore si sviluppa su due piani, tra loro indissociabili. Dal punto di vista del contenuto, il testo è innanzitutto un accorato e denso elogio della lingua francese e della sua straordinaria ricchezza espressiva. Dal punto di vista della forma, la ripresa del genere letterario del dialogo è declinata secondo un procedimento che richiama a tratti i Tropismi di Nathalie Sarraute. In effetti, gli interlocutori altro non sono che due diverse istanze dell'Io dell'autore: "Me", l'identità inglese, che potrebbe essere definita come originaria, e "Moi", la voce francese che gentilmente, ma implacabilmente, interviene per metterne in dubbio la solidità. Separati quel tanto che basta da contrapporsi nel gioco retorico del dialogo, "Me" e "Moi" sono le manifestazioni testuali di un soggetto che si riconosce come fragile, molteplice, scisso, e che nell'incontro con la lingua straniera trova la causa primaria della propria ambiguità: "Et l'cuvre d'une langue étrangère consiste à nous persuader [...] de l'existence de l'étrange au sein de l'habituel, d'un étrange à double face, attrayant ou alarmant. [...] Et de cette même étrangeté dans le moi. Si l'on change en plongeant dans les eaux d'une autre langue, le moi n'est pas stable, on peut se demander qui l'on est» (pp. 140-141). Il vero centro di interesse del volume è allora meno la lingua francese in sé che la lingua francese in quanto spazio da abitare e forza dalla quale lasciarsi abitare, elemento di estraneità in confronto al quale ripensare costantemente il proprio Io e il 
proprio rapporto con il reale: «Je suis la langue, les deux langues qui me connaissent intimement» (p. 41).

3 Le due voci si confrontano lungo sette capitoli che formano in realtà un'unica, lunga conversazione, delimitati soltanto da alcune indicazioni cronologiche e geografiche: "À Cambridge" (pp. 7-37), "Sur un punt" (pp. 39-69), "Le long de la rive” (pp. 71-104), "Durant la traversée" (pp. 105-120), "En bateau-mouche" (pp. 121-144), “Au square du Vert-Galant” (pp. 145-178), "Dans un bateau-restaurant” (pp. 179-210). Di pagina in pagina, il lettore assiste a un dialogo denso ma condotto con calviniana leggerezza, in cui la lingua francese è osservata nei suoi aspetti grammaticali, sintattici, ortografici, prosodici, retorici, ma anche etimologici, storici, sociologici (particolarmente d'effetto è la discussione della "texture historique, mémorielle», ovvero della capacità del linguaggio di preservare le tracce dei vari popoli che contribuiscono alla sua formazione, pp. 150-161). La storia letteraria offre all'autore un bacino pressoché illimitato dal quale attingere esempi nei quali la malleabilità della lingua appare in tutta la sua forza espressiva, ma i riferimenti al francese corrente, sia scritto sia parlato, sono altrettanto numerosi e spesso suscitano lo stesso effetto di sorpresa e suggestione.

In generale, il pur sentito elogio del francese condotto da Edwards non deriva assolutamente dalla volontà di affermare la superiorità di una lingua sulle altre. $\mathrm{Al}$ contrario: «Il a juste l'idée de réduire les autres langues, qui fait froid dans le dos [...] Chaque langue un monde, une symphonie, une respiration, une pensée, une façon de vivre» (pp. 124-125). Così come, sostiene l'autore, servono occhi e orecchie stranieri per cogliere alcune sottigliezze del francese, il confronto con la lingua straniera offre gli strumenti per osservare la propria con maggiore consapevolezza. Altrettanto, la riflessione sulla lingua (sia materna, sia straniera) appare innanzitutto come un momento di rottura importante, attraverso il quale lo scrittore può ripensarsi non solo in quanto studioso, ma in quanto soggetto di un mondo che sulla parola pone le basi della sua stessa esistenza. Domanda allora Me, in conclusione (p. 210): «N'as-tu pas l'impression que notre dialogue ressemble à ces conversations entre personnages secondaires qui ouvrent souvent les pièces de Shakespeare?». 